American Journal of Environmental Sciences 4 (6): 544-550, 2008

ISSN 1553-345X

(C) 2008 Science Publications

\title{
The Integration of Network-Based Models for Spill Response and Homeland Security
}

\author{
David E. Amstutz, Rakesh Bahadur, Jonathan M. Pickus, Michael C. Monteith, \\ Jeffrey P. Johnson, Christopher J. Ziemniak, Mondher Chehata, \\ Maria E. Herrera and William B. Samuels \\ Science Applications International Corporation, 1710 SAIC Drive McLean, VA 22102, USA
}

\begin{abstract}
The integration of three hydraulic GIS (Geographic Information System) applications is presented which represent the water infrastructures of cities and urban areas and US streams and rivers. The water infrastructures include drinking water distribution systems, wastewater collection systems and source water. The National Research Council ${ }^{[1]}$ states that problems dealing with the collective behavior of networks such as river systems, water distribution systems and waste water collection systems are complex because they include feedback loops, produce counter-intuitive behaviors and exhibit behaviors that cannot be predicted from the attributes of individual components. A complex system includes all of the above individual components, yet also exhibits emergent collective behavior caused by the interactions among its features. The integration of these applications have been developed for use in planning, response, training and development of monitoring strategies to address potential deliberate or accidental toxic contamination events.
\end{abstract}

Key words: Drinking water distribution, waste water collection, source water, hydraulic modeling

\section{INTRODUCTION}

Many of the streams and rivers in the US are sources for drinking water. Water from these surface sources are processed and distributed through pipelines throughout cities and suburbs. Wastewater is gathered with a second set of pipelines and treated and with the rain waters that wash buildings, malls and streets, is disposed of in the same streams and rivers. The streams and rivers and treatment and pipeline systems are each critical elements of water infrastructure.

One of the most significant actions taken in the US to protect critical infrastructure against criminal and terrorist attacks was the issuance in 1998 of Presidential Decision Directive $63 .{ }^{[2]}$ The directive designated the US EPA as the lead federal agency to address the water and wastewater infrastructure and work with both public and private organizations to develop emergency preparedness strategies. The US EPA appointed the Association of Metropolitan Water Agencies (AMWA) to coordinate the water industry's role in emergency preparedness. This coordination was broadened in 2001 to include both the drinking water and wastewater sectors. Recently, Homeland Security Presidential Directive (HSPD) 7 designated the US EPA as the sector-specific agency responsible for infrastructure protection activities for the nation's drinking water and wastewater systems . ${ }^{[3]}$ These directives specify the need to address two essential components in the protection of these systems: (1) the ability to accurately identify and locate critical components of the infrastructure and (2) the ability to present the data in a form that facilitates assessment of the primary and collateral consequences of an attack.

Despite strenuous efforts to protect public drinking water systems, they can still sometimes fail with tragic consequences. For example, in 1993, drinking water in Milwaukee, Wisconsin was accidentally contaminated with the pathogen, Cryptosporidium, resulting in over 100 deaths. Recent acts of terrorism, including the attacks on the World Trade Center and Pentagon and the dispersal of Anthrax in the US mails, illustrate the need to upgrade protection of drinking water to include defenses against deliberate terrorist acts as well as inadvertent water contamination.

There are two important ways to protect drinking water safety: (1) upgrade infrastructure to physically protect water supplies and (2) upgrade preparedness to take timely and effective action to minimize the

Corresponding Author: William B. Samuels, SAIC, 1710 SAIC Drive McLean, VA 22102, USA

Tel: (703) 676-8043 Fax: (703) 676-5323 
consequences to the public should an attack occur. Physical protection will be expensive, may take years to accomplish and at best provides only partial protection. Strengthening emergency response to attacks on drinking water can offer substantial and rapid gains in protection of public safety and civil order and can bolster security while infrastructure is being improved. Emergency response can be strengthened by (1) improving the speed and accuracy of detecting an attack and (2) providing personnel who direct the emergency response (Incident Commanders) with critical information to decide: who is at risk and what actions will most effectively reduce the risk. Furthermore, the use of water distribution and waste water collection system applications can also help quantify the consequences of possible pipeline failures that may result from aging infrastructures.

Three hydraulic GIS applications (network-based models) have been developed and integrated to address water infrastructure: water distribution, wastewater collection and source water (Fig. 1). In the past, these types of models have been developed and run independently. This study introduces the concept of integrated water security by including and hydrologically connecting each component of the water infrastructure: drinking water treatment and distribution systems, wastewater and runoff collection and treatment systems and the surface waters which serve for both source and disposal.

Water distribution: The US has approximately 180,000 water systems, serving over 250 million persons. ${ }^{[4]}$ An estimated 16 trillion gallons of water is processed annually by these US water utilities. All levels of government recognize that protecting the health and safety of the public requires safe drinking water and have invested heavily in drinking water systems to achieve this goal. According to the National Academy of Sciences. ${ }^{[5]}$ recent data on waterborne disease outbreaks suggest that distribution systems remain a source of contamination that has yet to be fully addressed.

Because water distribution systems are hyper complex structures, distinguished by extreme pressure gradients, spatial extensiveness and other physicalhydraulic variables, monitoring and/or predicting the fate and transport of introduced contaminants is a challenging proposition. Understanding contaminants residence, behavior and fate in water distribution systems is critical for planning and managing cleanup and rehabilitation efforts, deciding when and how best to re-open contaminated systems and developing strategies to detect and/or guard against deliberate

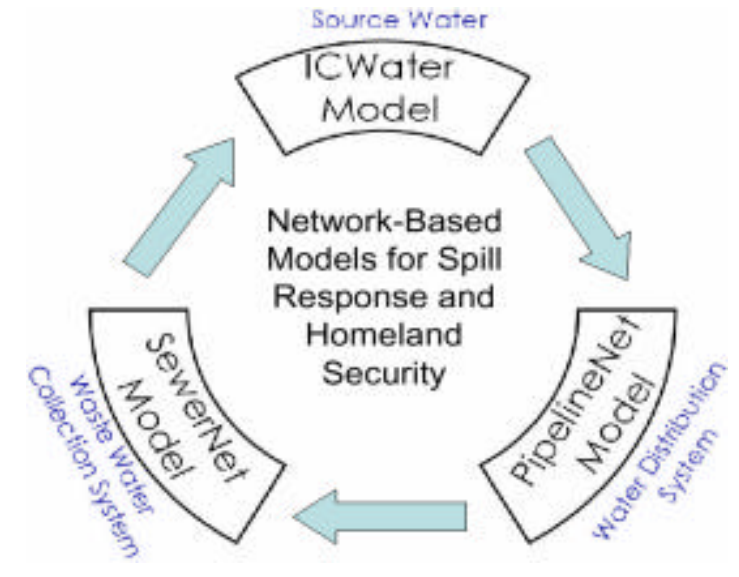

Fig. 1: Network-Based Models for source water, drinking water distribution systems and waste water collection systems

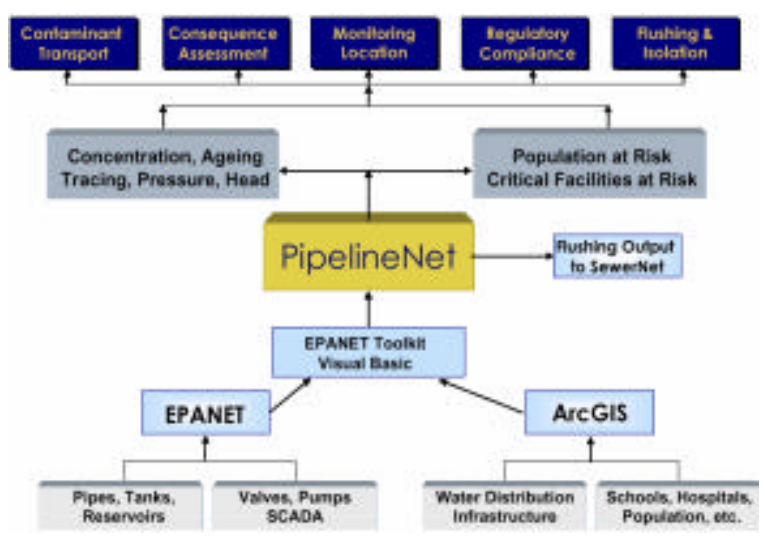

Fig. 2: Drinking water distribution system (PipelineNet) architecture

contamination. The prototype for the water distribution application was developed for use during the 2002Winter Olympics held in Salt Lake City and surrounding towns holding Olympic venues. ${ }^{[6]}$

The water distribution application (Fig. 2) is a network-based software tool with integrated data base capability that can be used to model the flow and concentration of contaminants in a city's drinking water pipeline infrastructure. ${ }^{[7,8]}$ The application contains a pipe network hydraulic model (EPANET), user defined and selected critical facility locations and a US Census population database. The application permits the user to model the flow and concentration of a biological, chemical or radiological agent within a city or municipal water system and calculate the population and critical facilities at risk. Time dependence of the flow reflects variation in water usage. 
The EPANET component of the application was developed by the Water Supply and Water Resources Division (formerly the Drinking Water Research Division) of the USEPA. ${ }^{[9]}$ EPANET performs an extended period simulation of hydraulic and water quality behavior within pressurized pipe networks consisting of pipes, nodes (pipe junctions), pumps, valves and storage tanks or reservoirs. The water distribution application is an integration of the EPANET hydraulic model and the ArcGIS 9.2 $2^{[10]}$ system. The integration is accomplished using the EPANET Toolkit, graphical user interfaces written in Visual Basic and ArcOBJECTS routines. The application has been developed for hydrologically oriented environmental decision support ${ }^{[11]}$ such as contaminant flushing (opening hydrants), system isolation (closing valves), sensor placement based on a hierarchical ranking scheme and queries that support the Initial Distribution System Evaluation (IDSE) guidance for stage 2 disinfection byproducts ${ }^{[12]}$

The water distribution application as adapted to various cities, has served to demonstrate its uses for monitoring chlorine residuals, following flow with a fluoride tracer and examining simplifications of pipeline networks (skeletonization). Skeletonization is the process most often used to select the most significant attributes of the hydraulic network that accurately represents the behavior of the system. The underlying assumption is that those portions of the network that are not modeled are accounted for within the parts of the system that are represented by the model. ${ }^{[13]}$ The water distribution application has also been applied to drinking water studies of large buildings and large venues. ${ }^{[14]}$

Wastewater collection: The US wastewater infrastructure is one of America's most valuable assets, valued at more than $\$ 2$ trillion. According to the US EPA, 190 million people are connected to 16,000 publicly owned treatment works) (POTW) 600,000 miles of municipal sewer pipes are in existence and 3,000 systems serve major metropolitan areas ${ }^{[15]}$ Significant environmental damage, impact on recreation and contaminated water supplies can be attributed to losses in wastewater treatment. Security at wastewater plants may not have received the attention it should have in the past. Efforts are underway to protect this significant public investment by looking at such issues as guarding against intruders, preventing access to supervisory control and data acquisition (SCADA) systems and developing emergency response plans. ${ }^{[16]}$

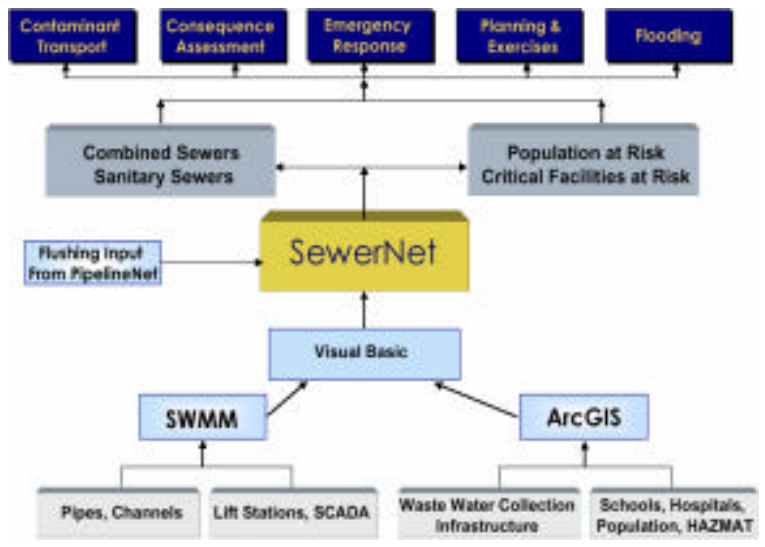

Fig. 3: Waste water collection system (SewerNet) architecture

The wastewater collection system application shown in Fig. 3 is a GIS-based consequence assessment tool used to evaluate the effects of contamination events on wastewater collection system performance. ${ }^{[17]}$ The US EPA Storm Water Management Model (SWMM $5.0)^{[18]}$ provides the hydraulic analyses, which are then used to calculate consequences to critical facilities and population. A post-processing component of the application reports the critical facilities and population affected by the hydraulic analysis. In addition to an included agent database of chemical, biological and radiological contaminants, the wastewater application includes a secure on-line link to access EPA's Water Contamination Information Tool. ${ }^{[19]}$ The resulting analysis supports utilities participating in planning exercises, rapid response to emergencies, or assessing the consequences to population and critical facilities. The wastewater application is applicable to any sanitary, storm or combined sewer system.

Contamination scenarios include: a direct release of a chemical or biological agent into a manhole or other entry point of the sewer system; the collection of contaminated water flushed from hydrants or other devices connected to a drinking water distribution system; or the collection of wastewater generated from normal activities occurring in homes, businesses and other facilities that might have received contaminated drinking water.

The wastewater collection application treats drainage networks of any size. The hydraulic model deals with a wide variety of standard open and closed conduit shapes as well as open channels and addresses storage/treatment units, flow dividers, pumps, weirs and orifices. External flows and water quality inputs may come from surface runoff, groundwater interflow, 


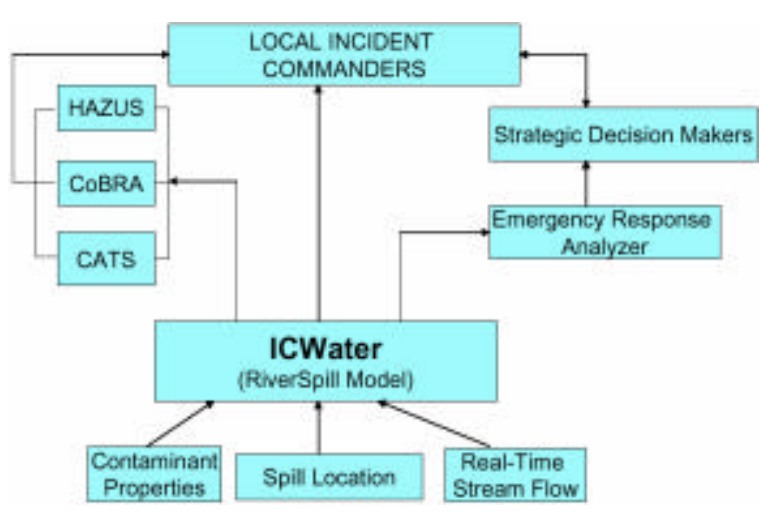

Fig. 4: Source water application (ICWater) concept of operations

rainfall dependent infiltration/inflow, dry weather sanitary flow and user defined inflows. Both kinematic wave and full dynamic wave flow routing methods may be used. Dynamic control rules to simulate the operation of pumps, orifice openings and weir crest levels are user-defined.

Source water: Surface water is a significant source $(62 \%)$ of drinking water in the US. ${ }^{[20]}$ In addition to the US EPA, the US Forest Service has a strong interest in drinking water protection since over 3,000 towns and cities are supplied with fresh water by streams and rivers that flow through Forest Service lands. ${ }^{[21]}$

The source water application (ICWater) (Fig. 4) focuses on providing Incident Commanders with critical information they need to protect the public during contamination attacks on drinking water. It was also designed to be compatible (through a commo n GIS platform) with other desktop emergency response tools such as the Consequences Assessment Tool Set ${ }^{[22]}$ (CATS) and the Hazards US (HAZUS) multi-hazard tool. ${ }^{[23]}$ Furthermore, web-based and web services versions provide compatible output to Internet-based systems such as EPA's Emergency Response Analyzer ${ }^{[24]}$ and the Chemical and Biological Response Aid (COBRA). ${ }^{[25]}$ The application consists of the National Hydrography Dataset Plus (NHD Plus), the USGS realtime stream flow gauging network, ARCGIS, agent and asset databases and the hydraulic model, RiverSpill.

The NHD Plus ${ }^{[26]}$ contains more than 3 million stream and river reaches, all hydrologically connected. Dams are included as one of the asset databases and can act as barriers in the network. Long-term average values of velocity and flow (discharge) are attributes of the NHD Plus reported for each reach.

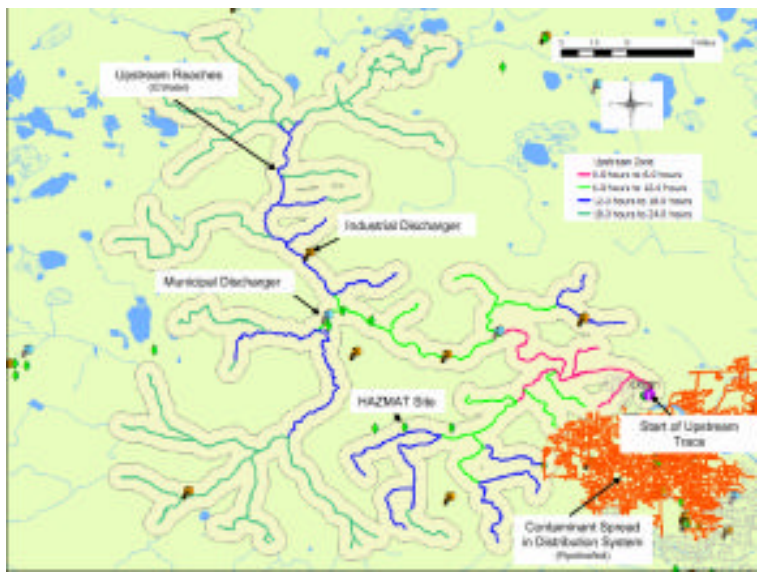

Fig. 5: Contaminant spread through the distribution system (PipelineNet) and upstream tracing (ICWater) from the water intake (buffering along the streams is for appearance only)

The real-time gages report stream and river flow from approximately 7,000 sites located throughout the US The agent database contains more than 200 toxic substances and includes chemical, biological and radiological agents. A level of concern and half-life is included for each of the substances, along with the reference for each of these values. Asset databases are included which represent the transportation networks, dams, schools and hospitals, storage locations for potentially toxic substances, water intakes and treatment facility locations and wastewater treatment and disposal sites.

RiverSpill ${ }^{[27,28]}$ is used to calculate the flow and dispersion of contaminants. RiverSpill uses a relationship between river velocity and river flow to determine the real-time velocity from the measured (gauged) real-time flow. The relationship between river velocity and river flow was determined empirically ${ }^{[29]}$ and theoretically. ${ }^{[30]}$ The calculations use the ratio of real-time velocity to long-term average velocity for extrapolation to river reaches not represented by the real-time gage network. ${ }^{[30,31]}$

Network integration: The three separate networkbased models for water distribution, wastewater collection and source water function together, enabling analyses of possible contamination events which affect more than one component of the water infrastructure.

An example of the upstream tracing of a river borne contaminant coupled with its spread through the distribution system is shown in Fig. 5. In the event depicted in Fig. 5, a toxic substance has entered the water distribution system through the intake. 


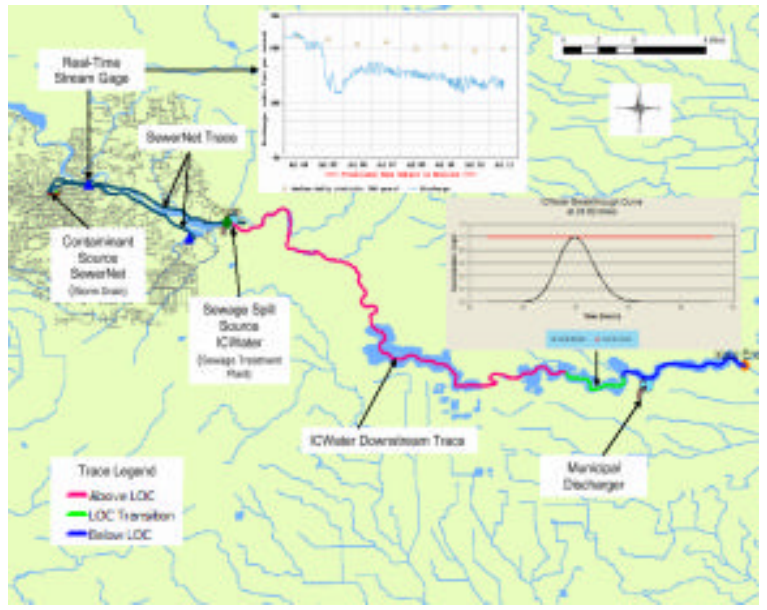

Fig. 6: Contaminant tracing trough the storm drainage network (SewerNet) followed by downstream tracing (ICWater) from the sewage treatment plant outfall

The PipelineNet model was used to calculate the contaminant spread through the pipe network. In the GIS, overlays of population and critical facilities provides for an assessment of the consequences of the event. Given that the source of the contamination may not be known, the question is asked, where might the substance have entered the river above the municipal water intake? ICWater is used to trace upstream, for the case shown in Fig. 5 using time-of-travel (based on stream flow), in an attempt to identify possible sources. In this scenario, the connection between the two models (PipelineNet and ICWater) is the drinking water intake. It serves as the starting point for calculating the contaminant spread through the distribution system and the upstream tracing of the river network.

The integration of these models is extended in the event that the contaminated drinking water is flushed from the system by opening a hydrant. In this case, the release of contaminated drinking water flows from the hydrant to the nearest storm drain and then into the storm sewer system (Fig. 6). Coupling of the PipelineNet and SewerNet models occurs by associating the flushing node (hydrant) in PipelineNet with the nearest input node (s torm drain) in SewerNet. In Fig. 6 the contaminated water, depicted by SewerNet, flows to the sewage treatment plant and into the river through the outfall. The ICWater application then traces the transport and dispersion of the contaminant downstream. The connection between the SewerNet and ICWater models is the sewage treatment plant outfall. Data from the real-time gauging station (used to calculate time-of-travel) and the time dependant contaminant concentration are also shown in Fig. 6. The downstream trace is segmented into three regions based on whether the peak concentration is above, at, or below the Level Of Concern (LOC) for the contaminant.

\section{CONCLUSION}

The three network-based software tools model the flow and dispersion of contaminants through water distribution systems, waste water collection systems and source waters. The tools have demonstrated utility for spill response and homeland security through application to international and national events such as the 2002 Winter Olympics and 2004 Republication National Convention. The modeling engines within the three applications, EPANET, SWMM and RiverSpill, have proven themselves in use and are judged to be applicable for planning and response. The utility of these applications is increased substantially by inclusion of highway, railroad and pipeline transportation networks as potential sources of spills. In addition, population statistics, agent databases and hyperlinks to relevant data sources (HAZMAT sites, dams, gages, municipal and industrial dischargers and drinking water systems) provide data for consequence assessment.

\section{ACKNOWLEDGEMENT}

We are grateful to several agencies for their support in developing and applying the three waterborne transport applications: FEMA (Federal Emergency Management Agency), USEPA (US Environmental Protection Agency), TSWG (Technical Support Working Group), USFS (US Forest Service), AwwaRF (American Water Works Association Research Foundation) and WERF (Water Environment Research Foundation). Several individual cities have also sponsored use of the water distribution and wastewater collection applications. Training for source water application users is provided by DTRA (Defense Threat Reduction Agency).

\section{REFERENCES}

1. NRC, 2005. Network Science, Committee on Network Science for Future Army Applications. National Research Council, Washington, DC., USA., pp: 124.

2. Presidential Decision Directive (PDD) 63. 1998. Critical Infrastructure Protection, May 22, 1998, http://www.fas.org/irp/offdocs/pdd-63.htm. 
Am. J. Environ. Sci., 4 (6): 544-550, 2008

3. Homeland Security Presidential Directive, 2003. Critical Infrastructure Identification, Prioritization and Protection, December 17. http://www.fas.org/irp/offdocs/nspd/hspd-7.html.

4. Rycus, M.J. and J.C. Snyder, 2001. Protection of Public Water Systems, Emergency Response and Water System Security in Germany, Israel and Japan and Vulnerability of Public Water System Supervisory Control and Data Acquisition (SCADA) Systems; prepared for the President's Commission on Critical Infrastructure Protection by The Studies in Urban Security Group (SUSG).

5. NAS, 2006., Drinking Water Distribution Systems: Assessing and Reducing Risks, National Academy of Sciences, Washington, DC., USA., pp: 204.

6. Bahadur, R., J. Pickus, D. Amstutz and W. Samuels, 2001. A GIS-based water distribution system for Salt Lake City, UT. Proceeding of the 21st Annual Conference on Environmental Systems Research Institute (ESRI) User, July 9-13, 2001, San Diego, CA.

7. Bahadur, R., W.B. Samuels and W. Grayman, 2001. EPANET-Arcview Integration for Emergency Response, Proceeding of the ASCE Congress on World Water and Environmental Resources, , May 20-24, Orlando, FL.

8. Bahadur, R., W.B., Samuels, W. Grayman, D. Amstutz and J. Pickus, 2003. PipelineNet: A model for monitoring introduced contaminants in a distribution system. Proceeding of the Congress on World Water and Environmental Resources, June 23-26, Philadelphia, PA.

9. Rossman, L.A., 2000. EPANET 2 User's Manual, National Risk Management Research Laboratory, Office of Research and Development, EPA Publication EPA/600/R-00/057, pp: 200.

10. ESRI, 2006. ArcGIS 9, What is ArcGIS 9.2, Environmental Research Systems Institute, Redlands, CA., pp: 126.

11. Samuels, W.B., R. Bahadur, D. Amstutz and J. Pickus, 2003. PipelineNet: An extended period simulation hydraulic model for distribution system emergency response. Proceeding of the AWWA DSS: Distribution and Plant Operations Conference and Exposition, Sep. 28-Oct. 1, Portland, OR.

12. EPA, 2006. Initial Distribution System Evaluation Guidance Manual for the Final Stage 2 Disinfectants and Disinfection Byproducts Rule, U.S. Environmental Protection Agency, Office of Water, EPA 815-B-06-002, Washington, DC.
13. Janke, R., R. Murray, J. Uber, R. Bahadur, T. Taxon and W. Samuels, 2007. Using TEVA to assess impact of model skeletonization on contaminant consequence assessment and sensor placement design. Proceeding of the World Environmental and Water Resources Congress, Tampa, FL, May 15-19.

14. Science Applications International Corporation, 2006. Development of Protocols and Guidelines for the Prevention of Contamination of Drinking Water in Large Venues, Report submitted to the New York City Department of Health and Mental Hygiene, pp: 107.

15. EPA, 2004. Water Security, Basic Information. http://cfpub.epa.gov/safewater/watersecurity/basici nformation.cfm.

16. WERF, 2004. Emergency Response Plan, Guidance for Waste Water Systems. Water Environment Research Foundation, Alexandria, VA., pp: 83.

17. Bahadur, R., J.P. Johnson, M.C. Monteith, J.M. Pickus, W.B. Samuels and C.J. Ziemniak, 2007. Integrated GIS-Based Consequence Assessment Model for Sewer and Stormwater, Water Environment Research Foundation Final Report, Alexandria, VA ., pp: 50.

18. EPA, 2004. Storm water Management Model (SWMM). http://www.epa.gov/ednnrmrl/models/ swmm.

19. EPA, 2007. Water Contaminant Information Tool (WCIT) Fact Sheet., EPA 817-F-07-001, Washington, DC. USA.

20. CSS, 2006. US Water Supply and Distribution, Center for Sustainable Systems Factsheet, University of Michigan, Ann Arbor, MI.

21. Ryan, D., 2007. ICWater: A New Software Tool for Protecting the Nation's Drinking Water, USDA Forest Service Stream Notes.

22. DTRA, 2007. Assessment of Catastrophic Events Center (ACECenter). Defense Threat Reduction Agency.

23. FEMA, 2007. FEMA's Software Program for Estimating Potential Losses from Disasters. http://www.fema.gov/plan/prevent/hazus/.

24. ESRI, 2007. Environmental Protection Agency, Emergency Response Analyzer (ERA). http:// www.esri.com/industries/federal/gis -business/files/ epa.pdf.

25. DGI, 2007. Chemical and Biological Response Aid (COBRA). Defense Group, Inc.

26. HSC, 2006. National Hydrography Dataset Plus, Horizon Systems Corporation, http://www.horizonsystems.com/nhdplus. 
27. Samuels, W.B., R. Bahadur, J. Pickus, D. Amstutz and K. McCormack, 2003. RiverSpill: A real-time emergency response and planning tool., Proceeding of the Water Security in the 21st Century, July 30Aug. 1, Washington, DC., USA.

28. Samuels, W.B., R. Bahadur, M.C. Monteith, D.E. Amstutz, J.M. Pickus, K. Parker and D. Ryan, 2006. NHD, riverspill and the development of the incident command tool for drinking water protection. Water Resour. IMPACT, 8: 15-18. http://www.treesearch.fs.fed.us/pubs/25548.

29. Leopold, J.L. and T. Maddock, 1953. The hydraulic geometry of stream channels and some physiographic implications. http://geomorph.ldeo. columbia.edu/grg/bibliography/leopold1953/.
30. Samuels, W.B., D.A. Amstutz, R. Bahadur and J.M. Pickus, 2006. RiverSpill: A national application for drinking water protection, $J$. Hydraul. Eng. 132: 393-403.

31. Samuels, B., R. Bahadur, M. Monteith and D.E. Amstutz, 2006. Using NHDPLUS for reat time spill modeling. American Water Research Association (AWRA) Spring Meeting, May 810, Houston, TX. 